\title{
ОРГАНИЗАЦИОННАЯ МОДЕЛЬ МОНИТОРИНГА В КОНТЕКСТЕ НАЛОГОВОЙ БЕЗОПАСНОСТИ РЕГИОНА
}

\author{
(c) 2021 Мурзина Елена Александровна \\ кандидат экономических наук, доцент кафедры управления и права \\ Поволжский государственный технологический университет, Респ. Марий Эл, Йошкар-Ола \\ E-mail: elena.murzina@gmail.com \\ (c) 2021 Шемякина Марина Сергеевна \\ кандидат экономических наук, \\ доцент кафедры бухгалтерского учёта, налогов и экономической безопасности \\ Поволжский государственный технологический университет, Респ. Марий Эл, Йошкар-Ола \\ E-mail:sh.marina.s@gmail.com \\ (c) 2021 Щербакова Наталья Владимировна \\ кандидат экономических наук, \\ доцент кафедры бухгалтерского учёта, налогов и экономической безопасности \\ Поволжский государственный технологический университет, Респ. Марий Эл, Йошкар-Ола \\ E-mail: shchnataliya@gmail.com
}

Работа выполнена в рамках гранта Российского фонда фундаментальных исследований РФФИ 19-010-00620 А «Методология многоуровневого мониторинга и управления налоговой безопасности региона в целях обеспечения социальных обязательств государства в условиях бюджетного дефицита».

Налоговые поступления играют решающую роль в формировании средств государственного бюджета. Недостаточно просто обеспечить поступление налогов в бюджет, установить определенные значения налоговых ставок, ввести льготы для отдельных категории налогоплательщиков. Важно иметь так называемую обратную связь, позволяющую дать объективную оценку эффективности работы налоговой системы в целом. Именно использование института мониторинга позволяет увидеть, насколько качественно и слаженно работают компоненты системы, выявить их слабые стороны, направления корректировки, отследить динамику относительных и абсолютных показателей, а также установить прогнозные и референсные значения. Актуальность обозначенной темы определяется все более возрастающей ролью использования расчетных и прогнозных методов в процессе формирования эффективной налоговой системы государства. В статье рассматривается организационная модель мониторинга в системе налоговой безопасности региона.

Ключевые слова: налоги, налоговая безопасность, экономические отношения, мониторинг.

Мониторинг как институт управления и как объект научного исследования получил, на наш взгляд, достаточно широкое освещение в трудах ряда исследователей. Не останавливаясь на понятийном анализе, отметим его особенность, формирующую его интерес именно для нашего исследования. Мониторинг консолидирует в себе анализ, оценку и прогнозирование, то есть является мощнейшим инструментов управления. В целях налоговой безопасности мониторинг представляет ценность как управленческий инструмент сбора и обработки данных с последующим преобразованием их в адекватное управленческое решение.
Мониторинг как институт системы управления налоговой безопасностью региона включает в себя деятельность уполномоченных субъектов по формированию массива данных, то есть явлениях и протекающих в налоговой системе страны процессах. Также к институту мониторинга можно отнести деятельность по регистрации значимых данных. Качество и полнота первичных данных напрямую оказывает влияние на: результаты анализа заинтересованных субъектов, а также результаты прогнозирования в системе мониторинга налоговой безопасности региона. В глобальной перспективе, качество первичной информации и правильность ее ре- 
гистрации и обработки отразиться на реализации основных направлений налоговой политики страны в целом.

Выделяют основные требования к первичной информации, соблюдение которых должно дать гарантии достоверности и объективности, представленной для анализа и принятия управленческих решений данных:

Во-первых, требуется выделять совокупности анализируемых данных, не рассматривая отдельные фрагменты или элементы того или иного анализируемого явления. В настоящее время обеспечение этого требования возможно за счет формирования календаря сдачи налоговой отчетности.

Во-вторых, данные, полученные в результате наблюдения должны соответствовать фактам, отражать реальные экономико-социальные процессы. С точки зрения мониторинга в контексте налоговой безопасности, регистрация данных осуществляется на основе информации из налоговых деклараций, что предполагает их достоверность (конечно проблему недобросовестности налогоплательщиков при подаче налоговой декларации также нельзя исключить).

В третьих, полученная информация, данные для анализа должны быть сопоставимы по субъектам, объектам и времени. Если речь идет об анализе данных, полученных по общей системе налогообложения и специальных налоговых режимов, то сопоставимость информации должна учитываться.

В четвертых, получаемые данные должны подвергать оперативной обработки и анализу, чтобы принимаемые на их основе решения были актуальны и своевременны.

Сбор данных и их обработка осуществляется в рамках государственного статистического наблюдения, в том числе в рамках налоговой статистики. Налоговая статистика - это отдельная отрасль социально-экономической статистики, которая обеспечивает учет реализации нормативного обложения доходов (имущества) юридических и физических лиц, полноты и своевременности внесения налогов. Она собирает и анализирует виды и объекты обложения (суммы налогов, ставки, сроки и способы их уплаты).

Задача мониторинга не сводится только к отслеживанию движения денежных средств и процесса пополнения бюджетов разных уровней. Должно обеспечиваться динамическое на- блюдение за этими процессами. В налоговые органы поступают сведения о недоимках налогов и бюджетных платежей от организаций и населения. Статистика налоговых поступлений базируется на принципах справедливости, определенности, удобства, экономии. Функции статистики применительно к налоговой системе сводятся к следующему: 1) сбор и регистрация данных, отражающих процессы, происходящие в региональной экономике; 2) аналитическая обработка полученных данных; 3) выявление закономерностей в происходящих процессах; 4) определение изучение влияния внешних факторов на доходность бюджетов всех уровней. На наш взгляд, должна выполняться еще одна функция, а именно: 5) обеспечение индикативного мониторинга налоговой безопасности.

Таким образом, информационной основой мониторинга является массив информации, получаемый налоговыми органами в результате декларационной работы.

Система показателей, используемых для налогообложения представлена на рис. 1. Система представленных показателей лежит в основе формирования налогового паспорта региона в настоящее время. На наш взгляд, сложившаяся система выполняет функции сбора и обработки сведений, но не выполняет функцию прогнозирования, а значит не может быть полноценной системой мониторинга в целях обеспечения экономической и налоговой безопасности региона.

По нашему мнению, мониторинг в контексте налоговой безопасности должен осуществляться в разрезе следующих направлений функционирования налоговой системы, поддерживаемых данными налоговой статистики [1]:

- анализ налоговой базы налогов и сборов и её динамики в зависимости от макро- и микроэкономических тенденций и от изменения налоговой политики;

- анализ поступления налогов и сборов в целом по РФ и субъектам РФ, по уровням бюджетной системы, по видам экономической деятельности и по группам налогов;

- анализ недоимки и задолженности по налоговым платежам, пеням и налоговым санкциям, и их структуры по уровням бюджетной системы РФ;

- анализ эффективности контрольной работы и применяемых методов принудительного взыскания задолженности и реструктуризации. 


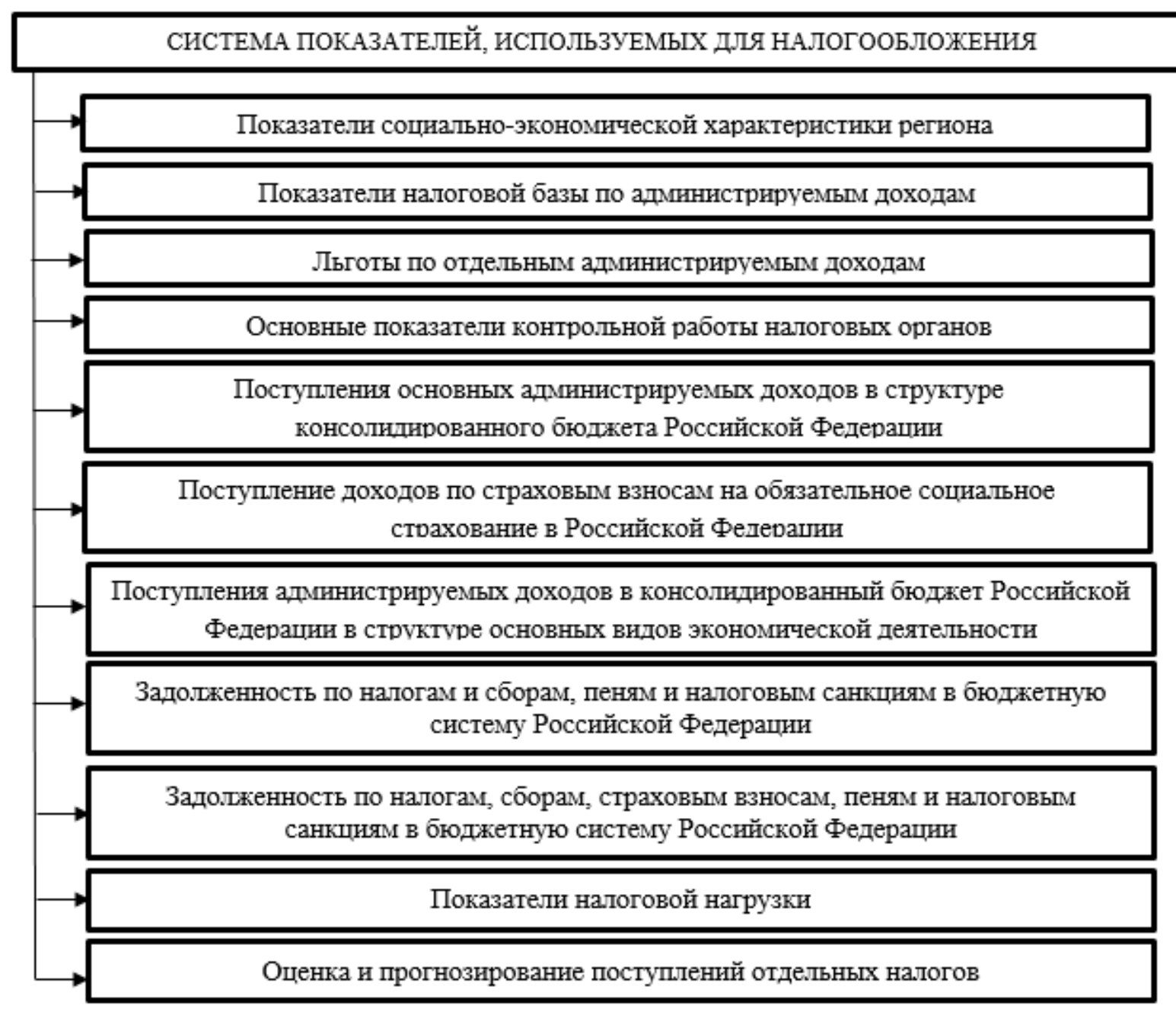

Puc. 1. Система показателей, используемых для налогообложения (разработана на основе Налогового паспорта региона)

Показателями, влияющими на результаты мониторинга и требующие учета:

- изменение объема валового внутреннего продукта, объемов выпускаемой продукции и оказанных услуг организациями и предпринимателями базовых отраслей экономики, объем прямых инвестиций в основной капитал;

- Показатели по динамике экспорта и импорта продукции, торговому обороту;

- финансовые результаты деятельности предприятия и организации (консолидированный результат), число прибыльных и убыточных предприятий.

Анализ отдельных видов налогов предусматривает изучение различных аспектов финансово-хозяйственной деятельности. В тоже время можно выделить ряд общих факторов, влияющих на величину налоговой базы.
При анализе факторов, влияющих на величину налоговой базы, можно выделить ряд показателей (рис. 2).

К числу факторов, существенно влияющих на изменение объема налоговых доходов государственного бюджета, относится изменение налоговых ставок и величины налоговой базы. Таким образом, может быть проведен факторный анализ и исчислено абсолютное и относительное изменение объема налоговых отчислений по каждому виду налога в отчетном периоде по сравнению с базисным за счет двух факторов: изменения объема налоговой базы и изменения налоговой ставки.

Формирование данных мониторинга основывается: а) регулярном сборе и анализе информации (сплошное наблюдение); б) на данных выборочного наблюдения (выборочное наблюдение). 


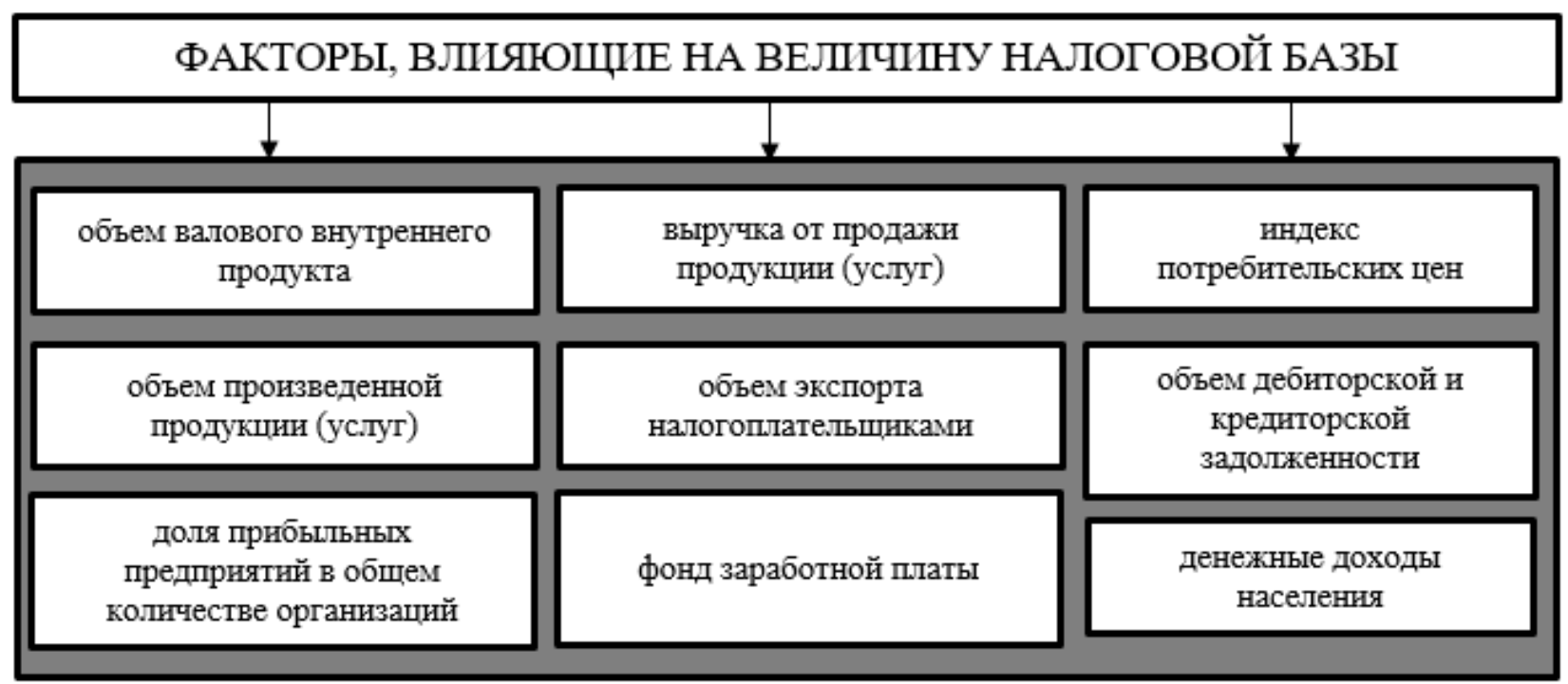

Puc. 2. Факторы, влияющие на величину налоговой базы

По времени регистрации признака определенный аналитический потенциал несут следующие виды наблюдения: а) периодическое (интервальное), в процессе которого сбор данных осуществляется в контексте декларационных компаний; б) непрерывное (не зависит от периодов предоставления налоговой отчетности).
В заключение отметим, что институт мониторинга является мощным масштабным инструментарием для обеспечения налоговой безопасности региона, в том числе позволяет отслеживать динамику показателей, выявлять особенности структуры явлений и приоритетные проблемы и отрасли развития.

\section{Библиографический список}

1. Назаров М.Г. Статистика финансов. Учебник. 6-е изд. / М. Г. Назаров.- М.: Омега-Л, 2011. - 516 с. - ISBN 978-5-370-01700-1.- URL: https://ibooks.ru/bookshelf/22153/reading (дата обращения: 19.10.2021).

2. Ажахова Д.А., Роль налогов в формировании доходной части бюджета Российской Федерации// International Journal of Humanities and Natural Sciences. - 2021. - vol. 6-1 (57). - C. 146-148

3. Васильченко А.Д., Налоговые поступления в бюджетную систему России: статистическая оценка и меры по мобилизации // Налоги и налогообложение. - 2019. - № 5. - C. 45-57. DOI: 10.7256/2454-065X.2019.5.30101 URL: https://nbpublish.com/library_read_article.php?id=30101

4. Графова T.О., Колесникова К.В., Прогнозирование поступлений федеральных налогов и сборов при помощи эконометрического моделирования // Инженерный вестник Дона. - 2020. - № 7, ivdon.ru/ru/magazine/ archive/n7y2020/6540

5. Ксенофонтов А.А., Контроль и регулирование финансово-экономической деятельностью регионов России// Инновации и инвестиции, 2020.- № 6. - С. 153-162.

6. Ксенофонтов А.А., Исследование экономического состояния регионов РФ и их видов экономической деятельности// Инновации и инвестиции. - 2018. - № 6. - С. 174-183

7. ууегреева Л.В., Наливкина В.В., оценка проблематики применения налогового администрирования в России на современном этапе развития экономики// Вестник Академии знаний. - 2019. - № 31 (2). - С. 288294.

8. Макашина О.В., Красникова Н.С., Алгоритм организации финансов государственного сектора// Известия ВУЗов. Серия «Экономика, финансы и управление производством». - 2020. - № 04(46). - С. 25-34.

9. Стешенко Ю.А., Типологизация отраслей народного хозяйства по уровню налогового стимулирования на основе кластеризации// Налоги и налогообложение. - 2018. - № 4. - С. 40-57. 